\title{
Hypoxia: involved but not essential for endometrial breakdown in mouse menstural-like model
}

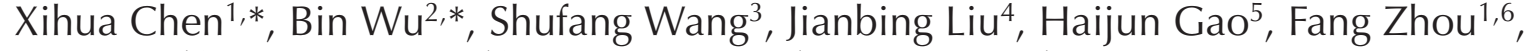

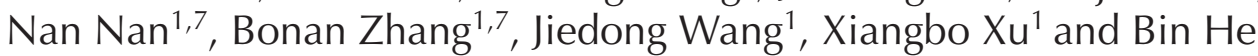 \\ ${ }^{1}$ Reproductive Physiology Laboratory, National Research Institute for Family Planning, Beijing, People's Republic of \\ China, ${ }^{2}$ Reproductive Medicine Department, Jinan Central Hospital Affiliated to Shandong University, Jinan, \\ Shandong Province, People's Republic of China, ${ }^{3}$ Department of Forensic Medicine, Xinxiang Medical University, \\ Xinxiang, Henan Province, People's Republic of China, ${ }^{4}$ Department of Cell Biology \& Genetics, Shanxi Medical \\ University, Taiyuan, Shanxi Province, People's Republic of China, ${ }^{5}$ Department of Obstetrics \& Gynecology, College \\ of Medicine, Howard University, Washington DC, USA, ${ }^{6}$ Male Clinical Laboratory, National Research Institute for \\ Family Planning, Beijing, People's Republic of China and 'Peking Union Medical College, Beijing, People's Republic \\ of China
}

Correspondence should be addressed to XXu or B He; Email: xiangboxuhappy@126.com or hebox@263.net

*(X Chen and B Wu contributed equally to this work)

\begin{abstract}
Menstruation is a specific physiological phenomenon that occurs in women. However, molecular mechanisms underlying this phenomenon are still unclear. According to the classical theory, tissue hypoxia resulting from vasoconstriction of the spiral arteries after progesterone (P4) withdrawal initiates the breakdown of the endometrium at the earliest stage of menstruation. However, this theory has been challenged by previous studies that have questioned the function and even the existence of hypoxia during menstruation. In this study, we not only provide convincing evidence that hypoxia exists during endometrial breakdown, but also further explore the role of hypoxia and hypoxia-inducible factor 1 (HIF1) in this process. Based on mouse menstrual-like model and experiments with human decidual stromal cells, we observed that P4 withdrawal induced both hypoxia and HIF1 activation; however, endometrial breakdown was triggered only by P4 withdrawal. Hypoxia significantly enhanced the mRNA expression of specific matrix metalloproteinases (MMPs) under the conditions of P4 withdrawal. In conclusion, hypoxia is involved but not an essential component of endometrial breakdown during menstruation.

Reproduction (2020) 159 133-144
\end{abstract}

\section{Introduction}

During each menstrual cycle, the functional layer of the human endometrium undergoes extensive breakdown and remodelling under the tight regulation of estrogen and progesterone. Although endometrial bleeding and shedding are important physiological events, the mechanisms underlying menstruation are still unclear.

The vascular response of the spiral arteries is considered to be the initiator of menstruation. The first classical model of menstruation to describe the vascular and endometrial changes was created by transplanting intraocular implants of the human endometrium into Rhesus monkeys (Markee 1940, 1978). Before the onset of menstruation (i.e. the release of blood), a 4-24 h period of vasoconstriction was observed. After approximately $24 \mathrm{~h}$, intense vasoconstriction followed by tissue necrosis was noted, which indicated that menstruation was triggered by spiral arteriole coiling. It was concluded that, in humans, endometrial breakdown was caused by tissue hypoxia resulting from vasoconstriction of the spiral arterioles. Many studies have explored the basis of hypoxia and its downstream regulation, mainly at cellular level, explant level and with mouse model of menstruation, and obtained interesting results (Critchley et al. 2006, Maybin et al. 2011a,b,c, 2018, Tsuzuki et al. 2012, Chen et al. 2015, Cousins et al. 2016).

However, a few studies have challenged Markee's theory. According to one study that used thermal and $133 \mathrm{Xe}$ clearance techniques, the endometrial blood flow did not decrease just prior to or during menstruation (Fraser et al. 1982). Recently, Gannon et al., using a laser Doppler technique, failed to find evidence of endometrial ischemia or perimenstrual perfusion at any time during the menstrual cycle in humans (Gannon et al. 1997). Further, in an in vitro study of human endometrial stromal cells, it was found that hypoxic conditions inhibited the production of 
proMMP-1, proMMP-3 and MT1-MMP, and inhibited the activation of proMMP-2, which are essential enzymes involved in the degradation of the extracellular matrix during endometrial breakdown (Zhang \& Salamonsen 2002). Coudyzer et al. using electron paramagnetic resonance oximetry technology and OxyLite to study the partial oxygen pressure caused by hormone withdrawal in a human endometrium xenograft model (Coudyzer et al. 2013). They observed the breakdown of the decidualized xenograft due to hormone withdrawal but could not detect any significant modification of $\mathrm{pO}_{2}$. The hypoxia marker pimonidazole was found only in a few xenografts. These results suggested that hypoxia was not focally increased, and that it was unlikely that hypoxia was induced prior to endometrial breakdown. However, several studies have provided relevant evidence to support the existence of hypoxia during menstruation. In murine model of menstruation, positive staining of pimonidazole was present at the leading edge of tissue growth 2 days after physiological P4 withdrawal (Fan et al. 2008), and also at $8 \mathrm{~h}$ and $24 \mathrm{~h}$, intense hypoxia was found in decidualized cell mass and the area of endometrial separation (Cousins et al. 2016, Maybin et al. 2018). These results of mouse models revealed the fact that physiological endometrial hypoxia exists in vivo. In addition, our previous study found that the key factor associated with hypoxia, the hypoxia-inducible factor 1 (HIF1) protein, was increased and activated during endometrial breakdown in a mouse menstrual-like model (Chen et al. 2015). It was also founded in human endometrium that the HIF1A level was highest during the menstrual phase in the nucleus (Critchley et al. 2006, Maybin et al. 2018). The recent study of Maybin et al. discovered menstrual endometrial HIF1A decreased in women with heavy menstrual bleeding, suggested HIF1A and hypoxia were relevant to endometrium repair. In mouse menstrual-like model, decreasing HIF1A induction by hyperoxia $\left(75 \% \mathrm{O}_{2}\right)$, by HIF1A inhibitor or in genetic were all able to delay endometrial repair, while stabilization of HIF1A rescued the repair process. This work confirmed the importance of hypoxia and HIF1A in normal endometrial repair, which was a big step forward in the field (Maybin et al. 2018). However, these results were primarily based on studies of murine models, and it is still uncertain whether hypoxia initiates endometrial breakdown in human menstruation.

The mouse menstrual-like model is an important model that enables the study of endometrial breakdown in real-time and allows for in vivo interference. The mouse menstrual-like model was first established in 1984 (Finn \& Pope 1984). In this model, P4 withdrawal led to endometrial breakdown after the stimulation of stromal cell decidualization with oil. The murine model was optimized in 2003 (Brasted et al. 2003). A few years later, in 2007, a model based on the pharmacological withdrawal of P4 was successfully established (Xu et al.
2007). Recently, studies using the mouse menstruallike model have shown interesting results regarding the mechanism of menstruation (Li et al. 2012, Xu \& He 2012, 2013, Wang et al. 2013, 2019, Wu et al. 2014, Chen et al. 2015, Maybin et al. 2018).

In this work, we further explored the roles of hypoxia and HIF1A in endometrium breakdown. In mouse menstrual-like model, immunohistochemistry staining revealed that hypoxia persisted from $0 \mathrm{~h}$ to $24 \mathrm{~h}$ after P4 withdrawal and intensify at $12 \mathrm{~h}$ and $16 \mathrm{~h}$; also, there was a strong correlation between hypoxia and HIF1A location. The global hypoxia seen in the mouse menstrual-like model was not able to initiate endometrial breakdown though the expression of HIF1A was promoted to some extent. In vitro study of human decidual endometrial stromal cells showed hypoxia significantly increased the mRNA expression of MMP$1,-3$ and -7 under the precondition of $\mathrm{P} 4$ withdrawal. These results suggest that hypoxia is not the initiator of endometrial breakdown, it probably assist the process.

\section{Materials and methods}

\section{Ethical approval}

All procedures for the animal study were approved by the Ethical Committee for Animal Welfare at the National Research Institute for Family Planning. Human tissue collection was completed after obtaining informed consent from all the patients in accordance with the Protocol for the Protection of Human Subjects approved by the Ethical Committee of the National Research Institute for Family Planning and the Declaration of Helsinki.

\section{In vivo mice experiments}

\section{Hypoxia detection and HIF1A immunohistochemistry}

The Hypoxyprobe ${ }^{\mathrm{TM}}$ compound pimonidazole, provided in the Hypoxyprobe ${ }^{\mathrm{TM}}-1$ Omni Kit (HP3-100KIT, Burlington, MA, USA), was used as a hypoxia marker as described previously (Raleigh et al. 1998). When the partial oxygen pressure is less than $10 \mathrm{mmHg}$, pimonidazole forms protein adducts that will combine and be marked by a specific antibody. Mice were administered Hypoxyprobe $(60 \mathrm{mg} / \mathrm{kg}$, i.p.) 30 min before being killed. Immunohistochemical analyses of Hypoxyprobe were performed according to the manufacturer's instructions.

Semi-quantification of the Hypoxyprobe staining scale. Three different sections from three mice from the $\mathrm{CoCl}_{2}{ }^{-}$and the $\mathrm{CoCl}_{2}^{+}$groups were randomly selected, and five random visual fields under 200× magnification were photographed (non-overlapping fields, without myometrium) in each section under the same microscopic settings (except focal length). The 3,3'-diaminobenzidine (DAB) staining area scale in each micrograph photo was calculated with the image processing program ImageJ (https://imagej.nih.gov/ij/); then, the corresponding statistical analysis was completed.

We also investigated the expression and localization of the HIF1A protein in the mouse menstrual-like model. Uterine 
histological cross-sections were dewaxed and rehydrated and the antigens were retrieved using citrate buffer $(\mathrm{pH} 6.0)$ at $95^{\circ} \mathrm{C}$ for $20 \mathrm{~min}$. The sections were soaked in $3 \%(\mathrm{v} / \mathrm{v}) \mathrm{H}_{2} \mathrm{O}_{2}$ for 15 min to quench endogenous peroxidase. Then we applied the anti-HIF1A primary antibody (1:500, Novus, Centennial, USA, NB100-479, AB_524183) and incubated the sections at $4^{\circ} \mathrm{C}$ overnight. After washing, the histological sections were incubated with the appropriate secondary antibody (Goat Anti-Rabbit-Enhanced Two-step Detection Kit, Zhong Shan Golden Bridge, Beijing, China, PV6100) and DAB (Zhong Shan Golden Bridge). Experiments were performed according to the manufacturer's instructions.

Semi-quantification of HIF1A nuclear staining. Five random visual fields under 200× magnification (non-overlapping fields, without myometrium) were photographed from each uterus section; the cell number and the HIF1A nuclear staining cell number were counted in each field by two researchers independently; then the corresponding statistical analysis was completed.

\section{Mouse menstrual-like model}

The mouse menstrual-like model was manipulated as described previously (Brasted et al. 2003, Xu et al. 2007). The 17b-Estradiol (E2) (Alfa Aesar Inc., Heysham, UK) and P4 (Sigma-Aldrich Inc.) used for s.c. injections were dissolved in arachis oil. The P4 silicone tubes were prepared as previously described (Milligan \& Cohen 1994), and each silicone tube contained approximately $15 \mathrm{mg}$ of P4 powder. Briefly, the mice were subjected to bilateral ovariectomy and were then allowed to recover for 2 weeks. From Day 1 to Day 3, all mice were subcutaneously injected daily with $100 \mathrm{ng}$ of E2 at 0930 h. Three days later, on Day 7, a silicone tube was subcutaneously implanted into the back of each mouse after $50 \mathrm{ng}$ of P4 and $5 \mathrm{ng}$ of E2 were administered (s.c.) at $0930 \mathrm{~h}$. On Days 8 and 9, 5 ng of E2 was injected (s.c.) at 0930 h; on Day 9 at $1130 \mathrm{~h}, 15 \mu \mathrm{L}$ of arachis oil was injected into the lumen of the uterine horn to induce decidualization. Then, 49 h later, endometrium decidualization was fully accomplished (designated as $0 \mathrm{~h}$ ) (Fig. 1A). The collected uteri were either fixed in $4 \%(\mathrm{~m} / \mathrm{v})$ paraformaldehyde (prepared in $\mathrm{PBS}, \mathrm{pH}$ 7.2) or frozen in liquid nitrogen and stored at $-80^{\circ} \mathrm{C}$ for further investigation.

\section{Study I}

The P4 silicone tubes were removed at $0 \mathrm{~h}$ to trigger $\mathrm{P} 4$ withdrawal. Mice were killed at $0(n=6), 8(n=5), 12(n=5)$, $16(n=5)$ and $24 \mathrm{~h}(n=6)$ after P4 withdrawal, and the uteri were collected (Fig. 1B). The localizations of Hypoxyprobe and the HIF1A protein staining were investigated using immunohistochemistry. The mice uteri were stained using hematoxylin and eosin (HE) to observe the histomorphology and endometrial breakdown.

\section{Study II}

Cobalt is a well-known chemical mimic of hypoxia-like responses, which can reduce the oxygen-carrying capacity of hemoglobin (Cain 1975) and suppress HIF1A degradation pathways (Yuan et al. 2003) in vivo. $\mathrm{CoCl}_{2}$ was administered to mice as described previously (Xi et al. 2004, Chen et al. 2007). The mouse menstrual-like model was established, and mice were separated into four groups: (1) P4 maintaining without

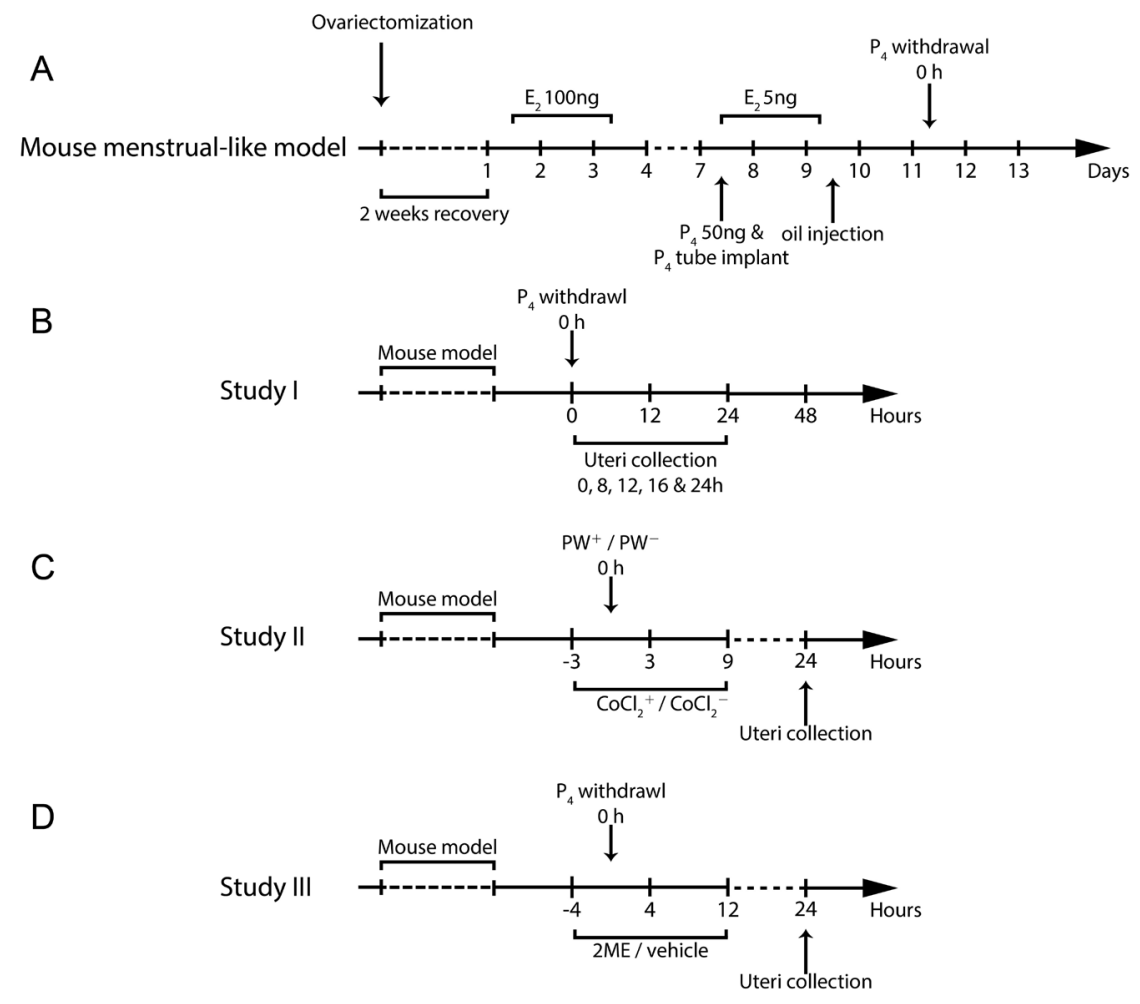

Figure 1 Mouse menstrual-like model experiments. (A) Establishment of mouse menstrual-like model. (B) Study I: Tissue collections at each time points. (C) Study II: Hypoxia mimic using $\mathrm{CoCl}_{2}$ (i.p.) with or without $\mathrm{P} 4$ withdrawal $\left(\mathrm{PW}^{+} / \mathrm{PW}^{-}\right)$. Uterine tissues were collected at 24 h. (D) Study III: HIF1A inhibition using 2ME (i.p.) and uterine tissue collection at $24 \mathrm{~h}$. 
$\mathrm{CoCl}_{2}$ administration $\left(\mathrm{PW}^{-} \mathrm{CoCl}_{2}^{-}, n=5\right)$; (2) P4 maintaining with $\mathrm{CoCl}_{2}$ administration ( $\mathrm{PW}^{-} \mathrm{CoCl}_{2}{ }^{+}, n=6$ ); (3) $\mathrm{P} 4$ withdrawal without $\mathrm{CoCl}_{2}$ administration $\left(\mathrm{PW}^{+} \mathrm{CoCl}_{2}{ }^{-}, n=5\right)$; and (4) $\mathrm{P} 4$ withdrawal with $\mathrm{CoCl}_{2}$ administration $\left(\mathrm{PW}^{+} \mathrm{CoCl}_{2}{ }^{+}, n=6\right)$. The administered dose of $\mathrm{CoCl}_{2}$ was $50 \mathrm{mg} / \mathrm{kg}$, and it was given by intraperitoneal injection (i.p.) three times at -3 h, 3 h, and 9 h. The mice uteri were collected at $24 \mathrm{~h}$ (Fig. 1C). The levels of the HIF1A protein in the cytoplasm and nucleus were investigated by a Western blot assay, while the localization of Hypoxyprobe and the HIF1A protein staining were investigated by immunohistochemistry. The mice uteri were stained using $\mathrm{HE}$ to observe the histomorphology and endometrial breakdown.

\section{Study III}

The HIF1A inhibitor 2-methoxyestradiol (2ME; Selleck, Houston, USA, S1233) (LaVallee et al. 2002, Escuin et al. 2005, Hu et al. 2013) was administered to mice as described previously (Chen et al. 2015). Briefly, 2ME was dissolved in DMSO (Sigma-Aldrich) and diluted with arachis oil. A dose of $100 \mathrm{mg} / \mathrm{kg}$ of $2 \mathrm{ME}$ was given to each mouse at $-4 \mathrm{~h}, 4 \mathrm{~h}$, and $12 \mathrm{~h}(n=6)$. The mice in the vehicle group were administered the corresponding amounts of a mixture of DMSO and arachis oil $(n=5)$. All mice were killed at $24 \mathrm{~h}$ (Fig. 1D). The mice uteri were fixed and HE-stained to evaluate the endometrial breakdown by relative breakdown area, given by, breakdown area/decidualized area. The breakdown area and decidualized areas were measured using ImageJ. The entire decidual and breakdown areas were selected manually by two researchers independently in ImageJ, the selected area size was calculated, and then the corresponding statistical analysis was completed.

\section{Decidualization and hypoxic culture of primary human endometrial stromal cells}

Endometrial tissue samples were obtained from surgical specimens of women with normal menstrual cycles (38-45 years old, $n=6$ ) undergoing hysterectomy for benign reasons; these women had not received any hormone treatment in the previous 3 months. The tissues samples used for this study were histologically designated as one of two phases, late-proliferative or early-secretory. The human endometrial stromal cells (hESCs) were prepared and cultured as described previously (Laird et al. 1997, Sugino et al. 2004). To induce in vitro decidualization, hESCs were cultured in a medium containing $2 \%(\mathrm{v} / \mathrm{v})$ charcoal-stripped FBS and antibiotics. They were treated with a hormone cocktail containing $100 \mathrm{nM}$ medroxyprogesterone (MPA) and $10 \mathrm{nM}$ E2 for 11 days, and the medium was changed every 48 h. After decidualization, the medium was replaced with hormone-free medium in the progesterone withdrawal group or with the hormonecontaining medium in the progesterone maintenance group. Both groups were maintained in normoxic conditions $(21 \%$ $\left.\mathrm{O}_{2}\right)$ or hypoxic conditions $\left(2 \% \mathrm{O}_{2}\right)$ in a sealed chamber (Thermo Fisher Scientific) that was flushed with a gas mixture of $2 \% \mathrm{O}_{2}, 5 \% \mathrm{CO}_{2}$, and $93 \% \mathrm{~N}_{2}(\mathrm{v} / \mathrm{v})$ at $37^{\circ} \mathrm{C}$. The cells were harvested $36 \mathrm{~h}$ after culturing in hypoxic conditions for RNA and nuclear protein extraction.

\section{Real-time PCR}

Total RNA from cultured hESCs was extracted using TRIzol (Invitrogen) according to the manufacturer's instructions. cDNA was synthesized with approximately $2 \mu \mathrm{g}$ of total RNA using reverse transcriptase (Takara Bio). Real-time PCR was performed on a StepOne ${ }^{T M}$ Real-time PCR System (ABI) using SYBR Premix Ex Taq ${ }^{\text {TM }}$ II (Takara Bio), and specific primers were used for each gene. The expression of $\beta$-ACTIN was used as an internal control. Thermal cycling conditions were as follows: an initial activation cycle at $95^{\circ} \mathrm{C}$ for $5 \mathrm{~min}$ followed by 40 cycles of denaturation $\left(95^{\circ} \mathrm{C}\right.$ for $\left.10 \mathrm{~s}\right)$, annealing, and amplification $\left(60^{\circ} \mathrm{C}\right.$ for $\left.34 \mathrm{~s}\right)$. The relative mRNA expressions of human MMP-1, MMP-2, MMP-3, MMP-7, MMP-9, and $M M P-13$ were determined. The primer sequences are shown in Table 1. All reactions were performed in triplicate. Relative quantification was performed using the $2^{-\Delta \Delta \mathrm{Ct}}$ approach, where $\Delta \Delta \mathrm{Ct}$ is the calibrated Ct value.

\section{Western blot analysis}

The HIF1A protein was detected by Western blot as previously described (Chen et al. 2015). The nuclear and cytoplasmic proteins were extracted with a nuclear extraction kit (NE-PER, Pierce, Thermo Scientific). Then, $15 \mu \mathrm{g}$ of cytoplasmic or nuclear protein was suspended in Laemmli buffer $125 \mathrm{mM}$ Tris- $\mathrm{HCl}, \mathrm{pH} 6.8,4 \%(\mathrm{w} / \mathrm{v})$ sodium dodecyl sulphate, $5 \%$ $(\mathrm{w} / \mathrm{v})$ 2-mercaptoethanol, 20\% (w/v) glycerol, and $0.05 \%(\mathrm{w} / \mathrm{v})$ bromophenol blue) in a ratio $2: 1(\mathrm{v} / \mathrm{v})$ and denatured at $95^{\circ} \mathrm{C}$ for $5 \mathrm{~min}$. The proteins were separated using 4-12\% (w/v) Bis-Tris gels (Nu-PAGE Novex; Invitrogen) and transferred onto PVDF membranes (Millipore). The membranes were blocked in 5\% (w/v) skim milk in TBS with Tween-20 for $1 \mathrm{~h}$ at room temperature. The membranes were incubated with an anti-HIF1A antibody (1:500, Novus, NB100-134, RRID: AB_350071). We used the anti- $\beta$-ACTIN antibody (1:2000, CoWin, Beijing, China) as an internal reference for cytoplasmic proteins and the anti-LAMIN-B1 antibody $(1: 200$, SC-20682, Santa Cruz Biotechnology) as an internal reference

Table 1 Primers used in real-time PCR analysis in human decidual stromal cells.

\begin{tabular}{|c|c|c|}
\hline Genes & Forward & Reverse \\
\hline$M M P-1$ & 5'-GGGAGATCATCGGGACAACTC-3' & 5'-GGGCCTGGTTGAAAAGCAT-3' \\
\hline$M M P-2$ & 5'-TGGCAAGTACGGCTTCTGTC-3' & 5'-TTCTTGTCGCGGTCGTAGTC-3' \\
\hline$M M P-3$ & 5'-ATGGACAAAGGATACAACAGGGACCAA-3' & 5'-TGTTGGCTGAGTGAAAGAGACCCAGG-3' \\
\hline MMP-7 & 5'-GAGATGCTCACTTCGATGAGG-3' & 5'-GGATCAGAGGAATGTCCCATAC-3' \\
\hline MMP-9 & 5'-CTTTGACAGCGACAAGAAGTGG-3' & 5'-GGCACTGAGGAATGATCTAAGC-3' \\
\hline$M M P-13$ & 5'-CACTTTATGCTTCCTGATGACG-3' & 5'-TCCTCGGAGACTGGTAATGG-3' \\
\hline$\beta-A C T I N$ & 5'-GCCGCCAGCTCACCATGGAT-3' & 5'-TGGGCCTCGTCGCCCACATA-3' \\
\hline
\end{tabular}


for the nuclear proteins. After washing, the membranes were incubated with HRP-conjugated mouse anti-rabbit IgG (1:10,000, Sigma-Aldrich Company Ltd.). The immunoreacted proteins on the membrane were then visualized using an enhanced chemiluminescence (ECL) system (Transgen, Beijing, China) on X-ray film.

\section{Statistical analysis}

The results are expressed as the mean \pm S.D. Statistical significance of the quantitative data was determined using the Student's t-test. Data that did not conform to the normal distribution were analyzed using the rank-sum test for significance. $P<0.05$ was considered significant.

\section{Results}

\section{Correlation between hypoxia and HIF1A during endometrial breakdown in mouse menstrual- like model}

We used Hypoxyprobe ${ }^{\text {TM }}$ staining to observe hypoxia distribution, and we used immunohistochemical staining to investigate HIF1A expression during endometrial breakdown in the mouse menstrual-like model (Fig. 2A). At $0 \mathrm{~h}$, hypoxia was localized in the luminal epithelium and a small area of sub-epithelial decidual stromal cells of the anti-mesometrial side. Small quantities of HIF1A were found primarily in the cytoplasm in the majority of the decidualized zone. But in the sub-epithelial decidual stromal cells, HIF1A was also found in the nucleus. At $8 \mathrm{~h}$, hypoxia was present in the entire decidualized zone, not limited in the subepithelium area. The expression of HIF1A increased in the cytoplasm of decidual stromal cells and could also be observed in the nucleus, especially in the luminal epithelial and sub-epithelial decidual stromal cells. At $12 \mathrm{~h}$, the hypoxic area was concentrated at the border between the intact decidual tissue and the outer edge of the necrotic area on the anti-mesometrial side. By $12 \mathrm{~h}$, the expression of HIF1A in the decidual tissue was similar to that in the hypoxic area. Additionally, the intensity of the positive nuclear staining of HIF1A also increased markedly. At $16 \mathrm{~h}$, the hypoxic area was concentrated at the outer edge of the necrotic area. At this point, the localization of HIF1A was similar to that of the hypoxic area, and it was located in many cell nuclei. At 24 h, Hypoxyprobe staining reduced and was only visible at the margin of the breakdown area and in the surface epithelium. Meanwhile, the expression of HIF1A dramatically weakened and its localization was limited to a small number of cells at the junction of the hypoxic regions, which was located in the nucleus. Semi-quantification further confirmed that the HIFA nuclear staining percentage significantly increased at $12 \mathrm{~h}(P<0.05)$ and $16 \mathrm{~h}(P<0.01)$ after $\mathrm{P} 4$ withdrawal compared with $0 \mathrm{~h}$ (before P4 withdrawal) (Fig. 2B).
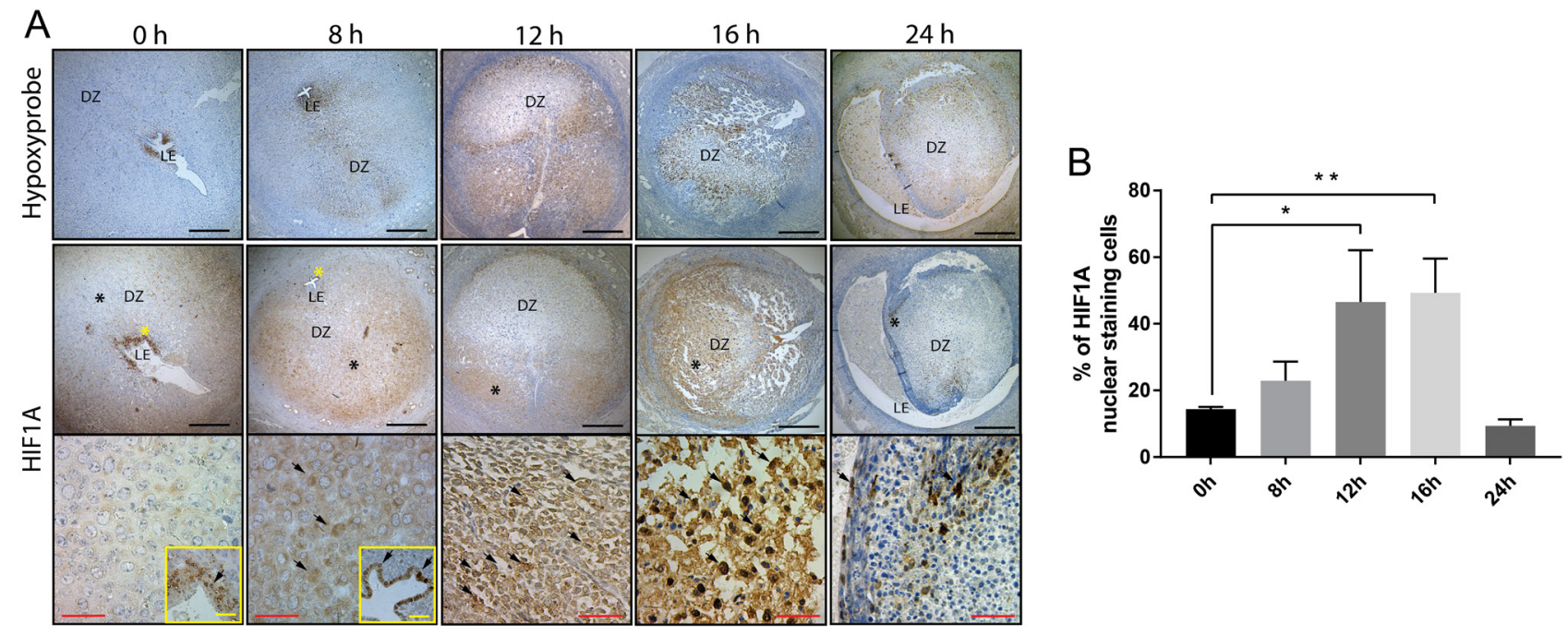

Figure 2 (A) Localization of Hypoxyprobe and HIF1A staining in mouse menstrual-like model from $0 \mathrm{~h}$ to $24 \mathrm{~h}$ after P4 withdrawal. Immunohistochemistry showed that at $0 \mathrm{~h}$, the hypoxic area centered at the luminal epithelium cells and sub-epithelial decidual stromal cells. Meanwhile, HIF1A was also located in nucleus at the hypoxic area. At $8 \mathrm{~h}$, both hypoxic area and HIF1A nuclear localization expanded to the decidual area. At $12 \mathrm{~h}$ and $16 \mathrm{~h}$, hypoxic area and HIF1A nuclear localization could be observed at the outer edge of the breakdown area and the remaining decidual area. At $24 \mathrm{~h}$, Hypoxyprobe staining decreased and remained at the marginal area of the breakdown endometrium, and HIF1A was observable at the junction of remaining decidual area located in the nucleus. Total replicates: $0 \mathrm{~h}(n=6), 8 \mathrm{~h}(n=5), 12 \mathrm{~h}(n=5), 16 \mathrm{~h}$ $(n=5)$, and $24 \mathrm{~h}(n=6)$. DZ, decidualised zone; LE, luminal epithelium. Arrows indicate HIF1A nuclear staining. Black asterisks $(*)$, magnified fields represented in black-boxes; yellow asterisks, magnified fields represented in yellow-box insets. Black scale bar $=400 \mu \mathrm{m}$, red scale $\mathrm{bar}=50 \mu \mathrm{m}$, yellow scale bar $=30 \mu \mathrm{m}$. (B) Semi-quantification of the percentage of HIF1A nuclear staining cells. The percentage of HIF1A nuclear staining cells significantly increased at $12 \mathrm{~h}$ and $16 \mathrm{~h}$ after P4 withdrawal compared with $0 \mathrm{~h}\left({ }^{*} P<0.05 ;{ }^{*} P<0.01\right)$. 


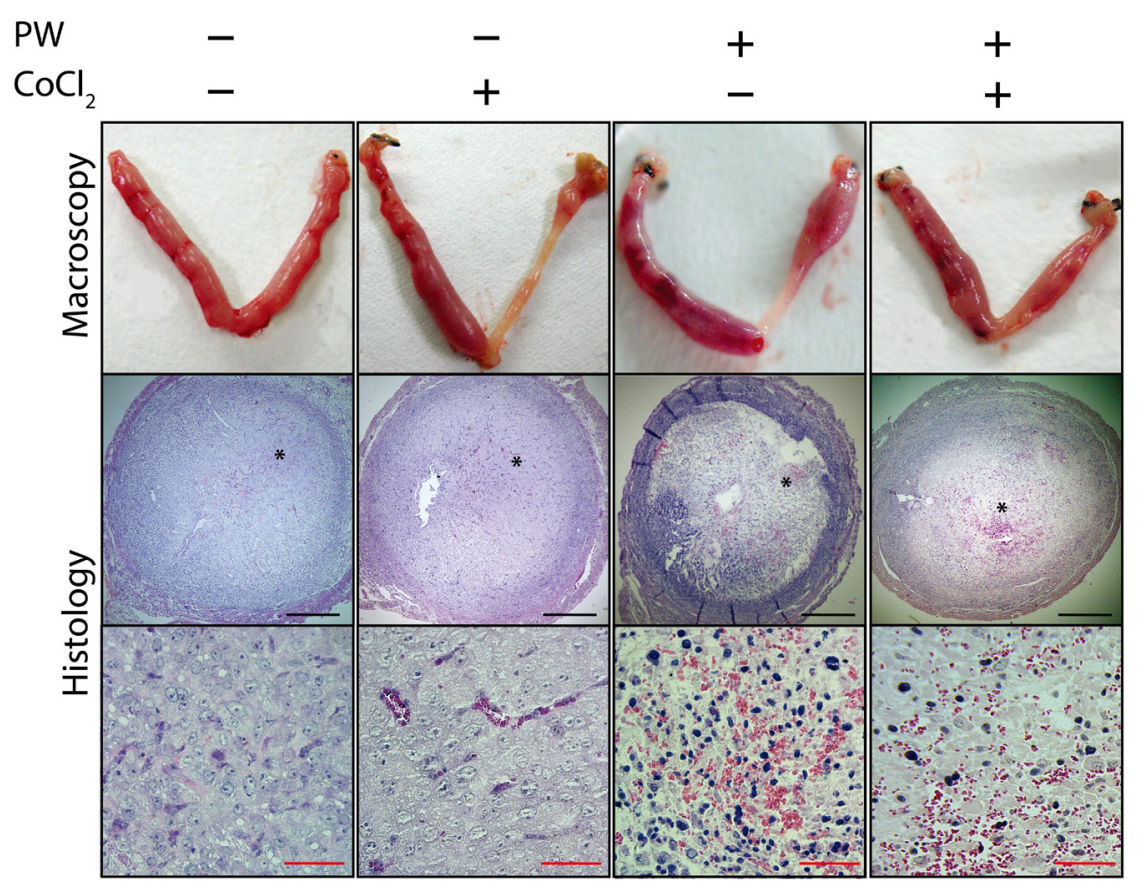

Figure 3 Macroscopic and microscopic morphology observation at $24 \mathrm{~h}$ in mouse menstrual-like model after global hypoxia mimic $\left(\mathrm{CoCl}_{2}{ }^{+}\right)$. In P4 maintain groups $\left(\mathrm{PW}^{-}\right)$, the decidual endometrium remained intact in both $\mathrm{CoCl}_{2}{ }^{-}$and $\mathrm{CoCl}_{2}{ }^{+}$groups. However, in $\mathrm{P} 4$ withdrawal groups $\left(\mathrm{PW}^{+}\right)$, decidual endometrium completely broke down and a large number of red blood cells exuded in both $\mathrm{CoCl}_{2}{ }^{-}$and $\mathrm{CoCl}_{2}{ }^{+}$groups. It shows that $\mathrm{CoCl}_{2}$-mimic hypoxia failed to trigger endometrial breakdown in mouse menstruallike model. Asterisks $\left({ }^{*}\right)$, magnified fields. Total replicates: $\mathrm{PW}^{-} \mathrm{CoCl}_{2}^{-}(n=5), \mathrm{PW}^{-} \mathrm{CoCl}_{2}^{+}$ $(n=6), \mathrm{PW}^{+} \mathrm{CoCl}_{2}{ }^{-}(n=5)$, and $\mathrm{PW}^{+} \mathrm{CoCl}_{2}{ }^{+}$ $(n=6)$. Black scale bar $=400 \mu \mathrm{m}$, red scale bar $=50 \mu \mathrm{m}$.

\section{Endometrial breakdown was triggered by $\mathrm{P} 4$ withdrawal rather than $\mathrm{CoCl}_{2}$-mimic hypoxia in the mouse model}

To investigate the role of hypoxia in the initiation of menstruation, we designed a group study with and without treatment incorporating a combination of progesterone withdrawal $\left(\mathrm{PW}^{+}\right.$or $\left.\mathrm{PW}^{-}\right)$and hypoxia mimic $\left(\mathrm{CoCl}_{2}{ }^{+}\right.$or $\left.\mathrm{CoCl}_{2}^{-}\right)$in mouse menstrual-like model. Specifically, four groups were classified as $\mathrm{PW}^{-} \mathrm{CoCl}_{2}^{-}, \mathrm{PW}^{-} \mathrm{CoCl}_{2}{ }^{+}, \mathrm{PW}^{+} \mathrm{CoCl}_{2}^{-}$, or $\mathrm{PW}^{+} \mathrm{CoCl}_{2}{ }^{+}$ (Fig. 3). In the $\mathrm{PW}^{-} \mathrm{CoCl}_{2}{ }^{-}$and $\mathrm{PW}^{-} \mathrm{CoCl}_{2}{ }^{+}$groups, the endometrial decidual stromal cells were intact, and vaginal bleeding was not detected. Notably, vasodilation was stronger in $\mathrm{PW}^{-} \mathrm{CoCl}_{2}{ }^{+}$than in $\mathrm{PW}^{-} \mathrm{CoCl}_{2}{ }^{-}$. Endometrial breakdown occurred in the $\mathrm{PW}^{+} \mathrm{CoCl}_{2}{ }^{-}$and $\mathrm{PW}^{+} \mathrm{CoCl}_{2}{ }^{+}$groups. The decidual stromal cells showed karyopyknosis and cytoplasmic degeneration, and universally lacked distinct cell borders. They also showed the exudation of a large number of red blood cells (Fig. 3). Vaginal bleeding could also be observed in mice in the $\mathrm{PW}^{+} \mathrm{CoCl}_{2}{ }^{-}$and $\mathrm{PW}^{+} \mathrm{CoCl}_{2}{ }^{+}$groups. These results clearly show that endometrial breakdown and bleeding did not take place under $\mathrm{PW}^{-}$conditions, regardless of the presence of $\mathrm{CoCl}_{2}$, but only occurred under $\mathrm{PW}^{+}$ conditions. The efficiency of $\mathrm{CoCl}_{2}$ as a hypoxia mimic in the mouse model was confirmed by Hypoxyprobe and HIF1A immunohistochemistry staining (Fig. 4). At $24 \mathrm{~h}$, in the $\mathrm{PW}^{-}$groups, under $\mathrm{CoCl}_{2}{ }^{-}$conditions, the hypoxic area was limited to the luminal epithelium and its surrounding areas, while the rest of the uterus did not exhibit hypoxia. In the $\mathrm{CoCl}_{2}{ }^{+}$condition, hypoxia was widely prevalent in the mouse endometrium, which was observed through the enhanced signal of Hypoxyprobe staining. HIF1A nuclear localization also significantly increased in the $\mathrm{CoCl}_{2}{ }^{+}$condition. Semi-quantification further confirmed that the Hypoxyprobe and HIFA nuclear staining percentage significantly increased with $\mathrm{CoCl}_{2}$ treatment (Fig. 4). Thus, $\mathrm{CoCl}_{2}$ was able to mimic hypoxia and activate nuclear translocation of HIF1A in the mouse menstrual-like model, suggests widespread hypoxia in the mouse uterus was successfully established.

\section{P4 withdrawal played an important role in HIF1A activation in the mouse model and in human decidual stromal cells}

We further compared cytoplasmic as well as nuclear HIF1A protein expression among different treatment groups (Fig. 5). In the $\mathrm{PW}^{-} \mathrm{CoCl}_{2}^{-}$group, HIF1A expression was high in the cytoplasm, but was barely detectable in the nucleus. In the $\mathrm{PW}^{-} \mathrm{CoCl}_{2}{ }^{+}$group, there was minimal change in HIF1A expression in the cytoplasm, which was lower than that of the $\mathrm{PW}^{-} \mathrm{CoCl}_{2}{ }^{-}$ group. Accordingly, HIF1A nuclear expression increased in the presence of $\mathrm{CoCl}_{2}$ in the $\mathrm{PW}^{-}$groups. These results suggest that the $\mathrm{CoCl}_{2}$-mimic hypoxia was able to promote the nuclear translocation of HIF1A. Although there was no significant change in the HIF1A expression in the cytoplasm of the $\mathrm{PW}^{+} \mathrm{CoCl}_{2}^{-}$group compared to that in the $\mathrm{PW}^{-} \mathrm{CoCl}_{2}^{-}$group, the expression was highest in the $\mathrm{PW}^{+} \mathrm{CoCl}_{2}{ }^{+}$group. In the two $\mathrm{PW}^{+}$groups, nuclear HIF1A was significantly higher than those in the two $\mathrm{PW}^{-}$groups. However, the nuclear expression of HIF1A in $\mathrm{PW}^{+} \mathrm{CoCl}_{2}^{+}$group was slightly higher than that in the $\mathrm{PW}^{+} \mathrm{CoCl}_{2}^{-}$group, but no significant difference was found. We concluded that P4 withdrawal significantly increased HIF1A nuclear translocation. 

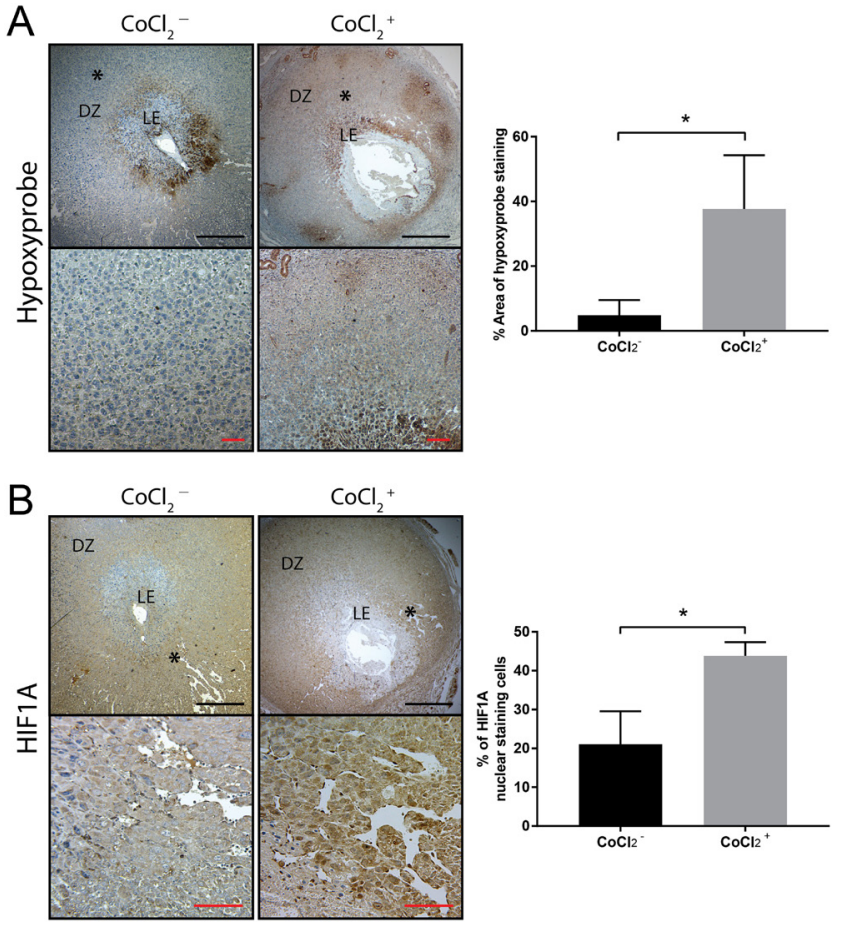

Figure 4 Validation of global hypoxia mimic by $\mathrm{CoCl}_{2}$. Immunohistochemistry staining of Hypoxyprobe and HIF1A was performed to investigate the effectiveness of hypoxia mimic in mouse menstrual-like model at $24 \mathrm{~h}(n=3)$. (A) Hypoxyprobe staining was stronger after $\mathrm{CoCl}_{2}$ treatment. Semi-quantification of Hypoxyprobe staining area scale indicates $\mathrm{CoCl}_{2}$ significantly increased hypoxic condition in mouse menstrual-like model. (B) HIF1A staining was stronger after $\mathrm{CoCl}_{2}$ treatment and located in nuclear. Semiquantification of the percentage of HIF1A nuclear staining cells indicates $\mathrm{CoCl}_{2}$ significantly increased HIF1A nuclear translocation in mouse menstrual-like model. DZ, decidualised zone; LE, luminal epithelium. Asterisks $(*)$, magnified fields. Black scale bar $=400 \mu \mathrm{m}$, red scale bar $=50 \mu \mathrm{m}\left({ }^{*} P<0.05\right)$.
Similarly, a study wherein the groups were subjected to a combination of progesterone withdrawal ${ }^{+}$, progesterone withdrawal ${ }^{-}$(PW) and hypoxia ${ }^{+}$, hypoxia ${ }^{-}$ (hypoxia-cultured) was also designed in human decidual stromal cells (Fig. 6A and B). In the $\mathrm{PW}^{-}$groups, HIF1A expression in the cytoplasm slightly decreased but significantly increased in the nucleus under hypoxic conditions. Moreover, in the two $\mathrm{PW}^{+}$groups, no significant changes in the cytoplasmic levels of HIF1A were found between hypoxia ${ }^{+}$and hypoxia ${ }^{-}$, but HIF1A nuclear expression significantly increased in hypoxia ${ }^{+}$ and was the highest in $\mathrm{PW}^{+}$hypoxia ${ }^{+}$conditions. In conclusion, similar results were found in both the mouse model and human decidual stromal cells, indicating that P4 withdrawal has a remarkably potent effect in HIF1A activation.

\section{P4 withdrawal initiates and hypoxia enhances the expression of MMPs in human decidual stromal cells}

We further investigated the expression of the mRNAs of different MMPs in the four study groups of human decidual stromal cells (Fig. 6C). In the two $\mathrm{PW}^{-}$groups, there were no significant differences in the expression of MMPs mRNA in either hypoxia ${ }^{+}$and hypoxia ${ }^{-}$group. However, the expression of MMP-1 and MMP-3 mRNA significantly increased over two-fold $(P<0.01)$ by $\mathrm{PW}^{+}$, while MMP-7 mRNA also increased slightly $(P<0.05)$, under hypoxia ${ }^{-}$conditions. In the $\mathrm{PW}^{+}$hypoxia ${ }^{+}$ group, $M M P-1$ expression was enhanced over fivefold $(P<0.01)$, and $M M P-3$ was enhanced over threefold $(P<0.01)$ compared to the $\mathrm{PW}^{-}$groups. These results indicate that although hypoxia did not trigger the expression of MMPS independently, it significantly enhanced the expression of MMP- 1 and MMP-3 after P4 withdrawal. There were no significant differences in the mRNA expression levels of MMP-2, MMP-9, and MMP13 among the different treatment groups.
A

A
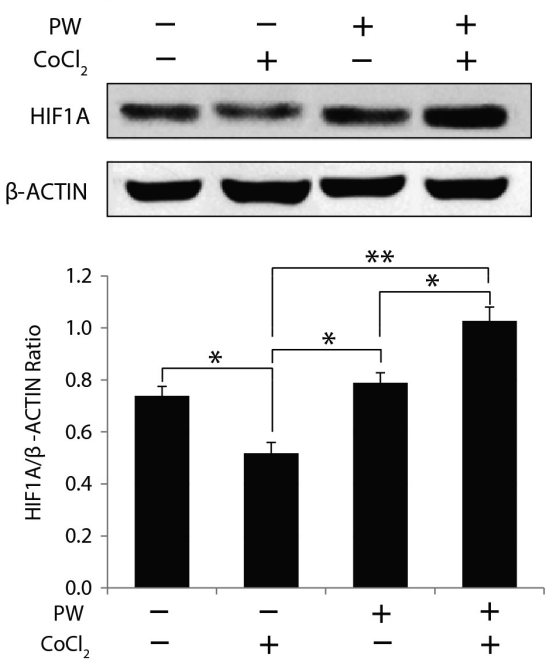

B

\begin{tabular}{|c|c|c|c|c|}
\hline \multirow[b]{2}{*}{ PW } & \\
\hline & - & - & + & + \\
\hline $\mathrm{CoCl}_{2}$ & - & + & - & + \\
\hline
\end{tabular}

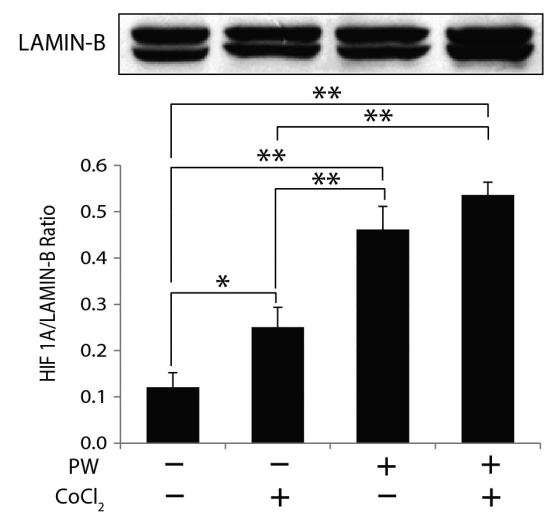

Figure 5 Expression of HIF1A in cytoplasm and nucleus after global hypoxia mimic in mouse menstrual-like model. Cytoplasmic and nuclear proteins were extracted separately, and HIF1A expression was investigated using Western blot analysis $(n=3)$. (A) HIF1A expression in cytoplasm. In P4 maintain groups $\left(\mathrm{PW}^{-}\right), \mathrm{CoCl}_{2}$ administration decreased HIF1A expression in cytoplasm, while in P4 withdrawal groups $\left(\mathrm{PW}^{+}\right)$, HIF1A expression in cytoplasm was increased by $\mathrm{CoCl}_{2}$ administration. (B) HIF1A expression in nucleus. In P4 maintain groups ( $\left.\mathrm{PW}^{-}\right)$, HIF1 A expression increased in nucleus after $\mathrm{CoCl}_{2}$ administration. However, the expressions in $\mathrm{P} 4$ withdrawal groups $\left(\mathrm{PW}^{+}\right)$were all significantly higher than those in $\mathrm{P} 4$ maintain groups $\left(\mathrm{PW}^{-}\right)\left({ }^{*} P<0.05 ;{ }^{* *} P<0.01\right)$. 

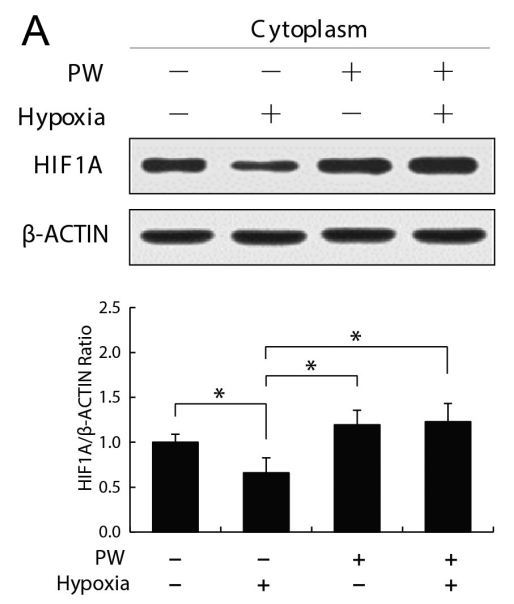
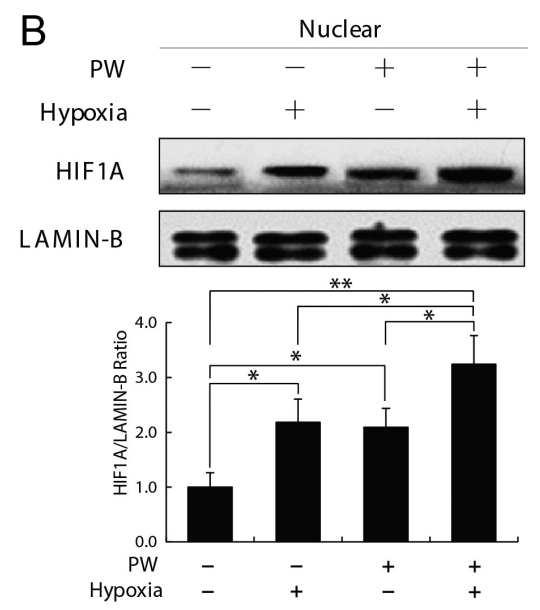

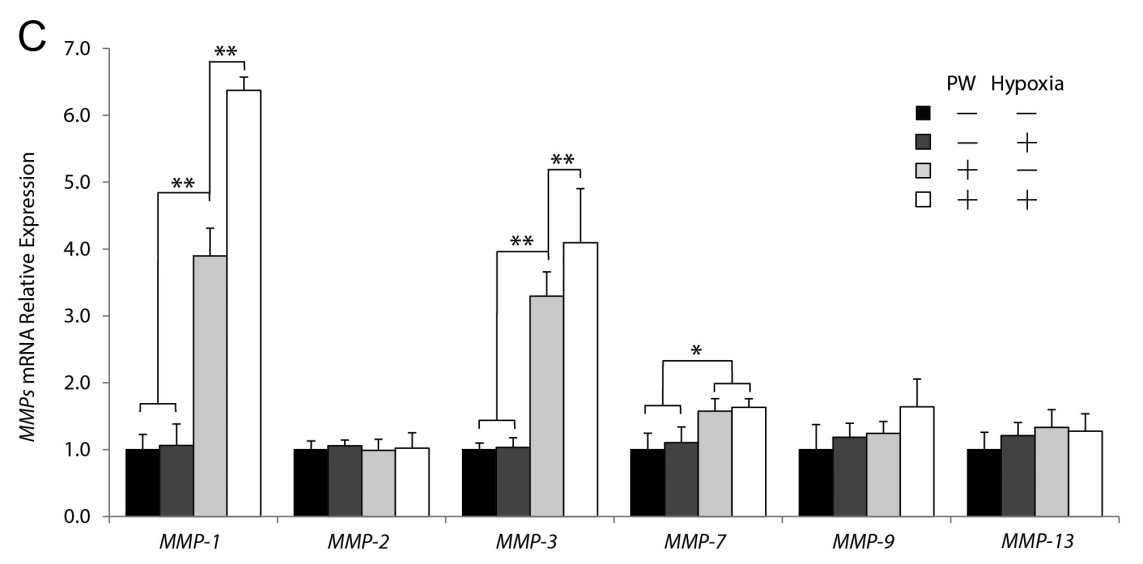

Figure 6 Expression of HIF1A protein and MMPS mRNA in decidualized human endometrial stromal cells. Cytoplasmic and nuclear proteins were extracted separately, and HIF1A expression was investigated using Western blot analysis $(n=3)$. (A) Expression of HIF1A in cytoplasm. HIF1A expression in decidualized stromal cells was decreased under hypoxic condition in $\mathrm{P} 4$ maintain groups $\left(\mathrm{PW}^{-}\right)$. However, no significant change was found in $\mathrm{P} 4$ withdrawal groups $\left(\mathrm{PW}^{+}\right)$. (B) Expression of HIF1A in nucleus. In both P4 maintain groups $\left(\mathrm{PW}^{-}\right)$and $\mathrm{P} 4$ withdrawal groups $\left(\mathrm{PW}^{+}\right)$, HIF1 A expression increased in nucleus under hypoxic condition, which was the highest in $\mathrm{PW}^{+} \mathrm{Hypoxia}^{+}$group. (C) mRNA relative expressions of $M M P-1, M M P-2$, MMP-3, MMP-7, MMP-9, and MMP-13 $(n=3)$. The mRNA expressions of MMP-1, MMP-3, and MMP-7 in $\mathrm{P} 4$ withdrawal $\left(\mathrm{PW}^{+}\right)$groups were significantly higher than those in $\mathrm{P} 4$ maintain groups $\left(\mathrm{PW}^{-}\right)$. Hypoxia further enhanced the expression of MMP-1, MMP-3 by $\mathrm{P} 4$ withdrawal $\left(\mathrm{PW}^{+}\right)$. No significant change was found in MMP-2, MMP-9, and MMP-13 $\left({ }^{*} P<0.05 ;{ }^{*} P<0.01\right)$.

\section{HIF1A plays an important role in endometrial breakdown in mouse menstrual-like model}

The HIF1A inhibitor $2 \mathrm{ME}$ was used to explore the function of HIF1A during endometrial breakdown. The mice were killed at $24 \mathrm{~h}$ after P4 withdrawal. Crosssections of the uteri were $\mathrm{HE}$-stained to observe the tissue histomorphology (Fig. 7A). The red borderline indicates the endometrial decidualization area, and the black borderline shows the endometrial disintegration area.

At $24 \mathrm{~h}$, the uterus from vehicle group showed a large area of endometrial disintegration and karyopyknosis along with tissue cytolysis, disintegration, and necrosis in many areas. The disintegration area was near the decidual zone, which showed substantial completion of endometrial breakdown. The disintegration process was similar to that observed at $24 \mathrm{~h}$ in mouse menstruallike mode with no treatment. However, after $2 \mathrm{ME}$ treatment, the ratio of disintegration area/decidualized endometrium area significantly decreased compared to that in the vehicle group $(P<0.01)$, whereas approximately half of the decidual zone was still intact (Fig. 7B). This indicates that $2 \mathrm{ME}$ significantly inhibited endometrial breakdown. Based on these observations, we suggest that P4 withdrawal leads to endometrial breakdown by activating HIF1A and its downstream genes during menstruation.

\section{Discussion}

The classical ischemia-reperfusion theory of menstruation by Markee was based on a hypothesis derived at a macroscopic observation level. However, the existence and function of hypoxia have been challenged by several studies. The exploration of the menstruation mechanism is limited due to the lack of suitable animal models and because it is difficult to collect tissue samples or perform interventions in humans. In our study, using the mouse menstrual-like model, we not only confirmed the existence of hypoxia but also explored its function, and elucidated the role of P4 withdrawal, hypoxia, and HIF1A in endometrial breakdown, both in vivo and in vitro.

Previous studies in the murine model of menstruation revealed that physiological hypoxia occurred in vivo applying the Hypoxyprobe pimonidazole. Hypoxyprobe staining was found in the stromal cells closest to the lumen and the luminal epithelial cells 2 days after P4 withdrawal (Fan et al. 2008), and also intensely in decidualized cell mass and the area of endometrial separation at $8 \mathrm{~h}$ and $24 \mathrm{~h}$ after P4 withdrawal (Cousins et al. 2016, Maybin et al. 2018). We have shown the distribution of hypoxia and HIF1A in mouse menstrual-like model at 0, 8, 12, 16 and $24 \mathrm{~h}$ after P4 withdrawal. It is notable that hypoxia was present at 0 

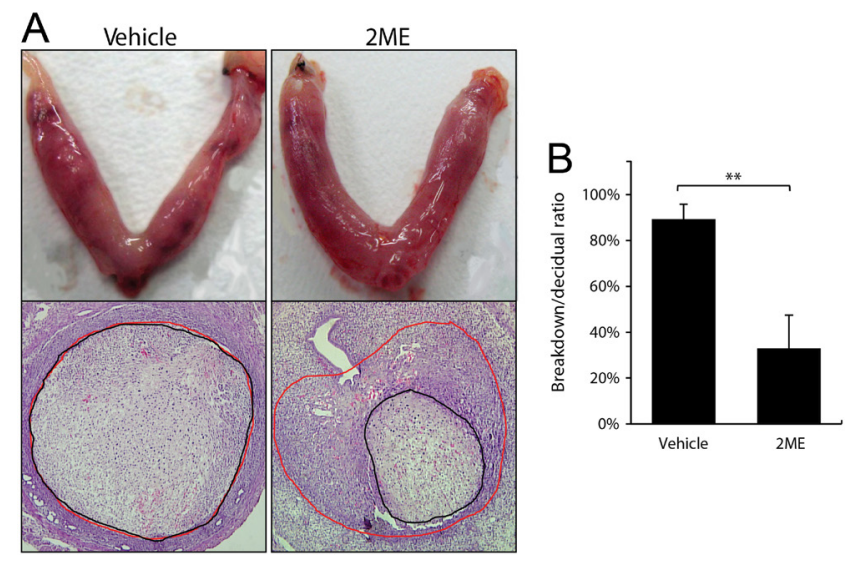

Figure 7 (A) Macroscopic and microscopic morphology observation of mouse menstrual-like model after HIF1A inhibition. At $24 \mathrm{~h}$, uterine hemorrhage of vehicle group was obvious compared with $2 \mathrm{ME}$ group. Endometrial breakdown area (black line) was significantly smaller in $2 \mathrm{ME}$ group. (B) The relative endometrial breakdown area in mouse menstrual-like model after HIF1A inhibition. The relative breakdown area was defined as the breakdown zone (black line)/the decidualized zone (red line), which was significantly suppressed in $2 \mathrm{ME}$ group $\left({ }^{* *} P<0.01\right)$. HIF1A inhibition significantly suppressed endometrial breakdown. Total replicates: $2 \mathrm{ME}(n=6)$ and Vehicle $(n=5)$.

h before P4 withdrawal and was found to be localized around the luminal epithelium, which was consistent with HIF1A nuclear staining. This characteristic is similar to the gestational decidual endometrium but without embryo stimulation. To our knowledge, this result has not been reported previously. Hypoxia is an important condition for trophoblast invasion that results in successful implantation (Cammas et al. 2005, Roh et al. 2005, Soares et al. 2012). Therefore, we suggest that the decidual uterus might proactively prepare for embryo implantation and trophoblast invasion.

Previous studies observed hypoxia in mouse menstrual-like model at $0,4,8$ and $24 \mathrm{~h}$ after P4 withdrawal (Cousins et al. 2016, Maybin et al. 2018). According to the studies of this model before, the decidualized endometrium remained intact until $8 \mathrm{~h}$, while endometrium breakdown was fully completed at $24 \mathrm{~h}$ (Xu et al. 2007, Wang et al. 2013, Wu et al. 2014, Chen et al. 2015, Cousins et al. 2016, Maybin et al. 2018). To find out the hypoxic changes of this process in detail, we investigate uterus hypoxia under a more elaborate time course by including the sampling time-points of $12 \mathrm{~h}$ and $16 \mathrm{~h}$. Our results show that the distribution of hypoxia gradually expanded to the whole decidual zone, and its intensity increased at $12 \mathrm{~h}$ and 16 $\mathrm{h}$ after P4 withdrawal, which provides strong evidence that hypoxia is involved in endometrial breakdown. Consistently, in the hypoxic area, correlated changes in the nuclear expression of HIF1A were seen. Especially at $12 \mathrm{~h}$, the immunohistochemical staining area of HIF1A was similar to that of Hypoxyprobe. A previous study using in mouse menstrual-like model revealed that replacement of $\mathrm{P} 4$ before $12 \mathrm{~h}$ suppressed endometrial breakdown, and it was inferred to be a critical period of P4 withdrawal (Wang et al. 2013). Our results confirmed the existence of hypoxia with specific spacetime changes after P4 withdrawal. Moreover, we saw a strong correlation between HIF1A nuclear translocation and hypoxia distribution, which implied that HIF1A was activated by hypoxia during endometrial breakdown.

A recent study by Maybin et al. explored the function of hypoxia by placing the murine model under hyperoxic conditions, and they found that endometrial repair was delayed. In this study, we explored a different route by mimic global hypoxia with $\mathrm{CoCl}_{2}$ administration in mouse menstrual-like model to determine whether hypoxia is the initiating factor of menstruation. In this study, 4 groups of mice were manipulated using P4 withdrawal ${ }^{+/-}$and $\mathrm{CoCl}_{2}$-mimic hypoxic ${ }^{+/}$conditions. The effectiveness of the $\mathrm{CoCl}_{2}$-mimic hypoxia was verified by Hypoxyprobe and HIF1A staining. The results clearly showed that the presence of acute hypoxia in the entire uterus did not affect the integrity of the decidual stromal zone. Endometrial breakdown occurred only under P4 withdrawal conditions, but not by the $\mathrm{CoCl}_{2}$-mimic hypoxia. Therefore, hypoxia was not able to initiate endometrial breakdown. However, the $\mathrm{CoCl}_{2}$-mimic hypoxia likely alters vascular permeability, thereby affecting blood vessels during endometrial breakdown. We concluded that while hypoxic conditions were not necessary for the initiation of endometrial breakdown, they possibly assist the process.

Both hypoxia and HIF1A were activated after P4 withdrawal, but hypoxia was not the key factor to trigger endometrial breakdown. In this study, the role of hypoxia in endometrial breakdown and whether HIF1A was activated by hypoxia were our primary interests. Using a xenograft menstruation model, a previous study showed that hypoxia, Hypoxyprobe and HIF1A staining could not be detected after ovarian hormone withdrawal (Coudyzer et al. 2013). However, in our study, Western blot results showed that HIF1A nuclear translocation was significantly increased by the $\mathrm{CoCl}_{2}$-mimic hypoxia in the absence of P4 withdrawal. Moreover, in the $\mathrm{P} 4$ withdrawal group, $\mathrm{CoCl}_{2}$ did not significantly affect HIF1A nuclear translocation when the protein expression was significantly enhanced in the cytoplasm. Interestingly, in the P4 withdrawal group, the expression of HIF1A in the nucleus was significantly increased irrespective of the hypoxic state. These results suggest that P4 withdrawal is an essential factor for HIF1A activation, and that hypoxia might be only a secondary enhancer of HIF1A (Coudyzer et al. 2013). Further in vitro studies performed in decidualized human stroma cells indicate that P4 withdrawal or hypoxia alone was able to activate HIF1A nuclear translocation, and the HIF1 A translocation was the highest under $\mathrm{P} 4$ withdrawal plus hypoxia conditions. These were different from the 
results in the murine model. The difference between the results of the in vivo and in vitro studies might due to the absence of 3D tissue structures and vascular structures in cultured cells; however, this is still unclear and needs further study. Critchley et al. previously proposed a hypothesis of the dual regulation of HIF1A in menstruation, according to which HIF1A may be regulated by both hypoxia-independent and hypoxiadependent pathways (Critchley et al. 2006). Our study provided experimental evidence for this hypothesis. P4 withdrawal activated HIF1A in the absence of hypoxia, thereby representing the hypoxia-independent pathway, while hypoxia-activated HIF1A without P4 withdrawal represents the hypoxia-dependent pathway, suggesting that these two pathways of HIF1A activation simultaneously exist during endometrial breakdown.

MMPs are the most important lytic enzymes that function during menstruation. A study conducted in menstruating macaques revealed the importance of MMPs in endometrial breakdown (Rudolph-Owen et al. 1998). P4 replacement at a critical time point suppressed MMP-1, -2 , and -3 expression along with the suppression of menstruation (Slayden \& Brenner 2006). However, in a study conducted by Zhang and Salamonsen, human endometrial cells were cultured with steroid withdrawal under hypoxic conditions. The hypoxic cultured cells were subjected to a normoxic recovery culture, and the results showed that active MMP-2, proMMP-1, and proMMP-3 production was inhibited in the hypoxia group (Zhang \& Salamonsen 2002). Similarly, a decrease in MMPs could be observed in the culture supernatants from whole endometrial explants after culturing under hypoxic conditions for $24 \mathrm{~h}$ (Gaide Chevronnay et al. 2010). Our in vitro results also suggested hypoxia did not affect the expression of MMPs mRNA in human decidual stromal cells. Therefore, these results do not support the major role of hypoxia in the regulation of tissue breakdown. Our results also showed that P4 withdrawal enhanced the levels of MMP-1, MMP-3 and MMP-7 $(P<0.01)$. These results are consistent with previous studies concerning MMP-1, -3 and -7 in menstruation (Gaide Chevronnay et al. 2012), in macaques (Slayden \& Brenner 2006), and in the murine model of menstruation (Wang et al. 2013). Interestingly, in this work, the effect of hypoxia accompanied by P4 withdrawal significantly enhanced the mRNA expression of MMP-1 and MMP3. This suggests that the expression of $M M P-1$ and $M M P-3$ was triggered by $\mathrm{P} 4$ withdrawal and enhanced by hypoxia, indicates hypoxia is involved in MMPs regulation after endometrial breakdown is activated.

Menstruation is an important physiological process that has great significance in female reproductive health. It is widely accepted that P4 withdrawal is the trigger for menstruation. However, the initiating and terminating factors of menstrual blood loss are still unclear. The process consists of a complex and delicate regulatory network involving immune, endocrine, and vascular systems (Maybin \& Critchley 2015). The mouse menstrual-like model that successfully mimics human menstruation, provides an operational platform to study the mechanisms of menstruation, and has been used considerably in recent years. However, there is a lot of difference between the vascular structures of the endometrium in mice and humans, especially the lack of spiral arterioles in mice, which should always be considered. Hypoxia is a factor that upregulates the expression of a number of genes involved in angiogenesis, mitogenesis, and metabolism (Maybin \& Critchley 2015), which highlight its physiological function (Zhang \& Salamonsen 2002, Fan et al. 2008, Coudyzer et al. 2013, Cousins et al. 2016, Maybin et al. 2018). Recently, Maybin et al. have proposed a noteworthy study that focuses on the role of Hypoxia and HIF1A in physiological endometrial repair, and they suggested that HIF1 could be an effective, nonhormonal treatment for heavy menstrual bleeding, which illustrates the significance of HIF1 (Maybin et al. 2018). However, whether hypoxia is the direct cause of endometrial breakdown is not yet resolved.

Endometrial repair is an important process in both normal and abnormal endometrial bleeding. In recent years, the functions of hypoxia and HIF1 A in physiological endometrial repair have been the focus of research; these have been gradually clarified. The results of our study strongly support the earlier study on this subject (Maybin et al. 2018) and further explore the function of hypoxia and HIF1A in a mouse menstrual-like model and human decidual stromal cells. We clarified the changes in hypoxia and HIF1A by using a more elaborate time course by including $12 \mathrm{~h}$ and $16 \mathrm{~h}$ after $\mathrm{P} 4$ withdrawal which was not investigated before and revealed the pre-existence of hypoxia in the decidual endometrium, the location consistency of hypoxic areas and HIF1A activation after $\mathrm{P} 4$ withdrawal. We employed $\mathrm{CoCl}_{2}$ to globally mimic hypoxia in the mouse menstrual-like model, which showed that endometrial breakdown was initiated by $\mathrm{P} 4$ withdrawal rather than by $\mathrm{CoCl}_{2}$-mimic hypoxia. This in vivo and in vitro evidence suggests that hypoxia participates but is nonessential for endometrial breakdown. Hypoxia is involved in MMPs expression and is able to significantly promote the expression of MMP-1, -3 mRNA under P4 withdrawal conditions; however, it is not able to independently trigger the expression of MMPs, as well as endometrial breakdown. An HIF1A inhibition study has also shown that HIF1A is an important factor that took part in endometrial breakdown. Although the function of Hypoxia in menstrual-like model and decidual endometrium stromal cells are investigated, the functional regulation of hypoxia by P4 withdrawal was not yet determined. In summary, our study provides further insights into the functional mechanism underlying menstruation. 


\section{Declaration of interest}

The authors declare that there is no conflict of interest that could be perceived as prejudicing the impartiality of the research reported.

\section{Funding}

This work was funded by the National Natural Science Foundation of China (No. 81571410), (No. 81601254), CAMS Innovation Fund for Medical (No. 2018-I2M-1-004) and Beijing Municipal Natural Science Foundation (No. 7152115).

\section{References}

Brasted M, White CA, Kennedy TG \& Salamonsen LA 2003 Mimicking the events of menstruation in the murine uterus. Biology of Reproduction 69 1273-1280. (https://doi.org/10.1095/biolreprod.103.016550)

Cain SM 1975 Oxygen delivery and utilization in dogs with a sublethal dose of cobalt chloride. Journal of Applied Physiology 38 20-25. (https:// doi.org/10.1152/jappl.1975.38.1.20)

Cammas L, Reinaud P, Dubois O, Bordas N, Germain G \& Charpigny G 2005 Identification of differentially regulated genes during elongation and early implantation in the ovine trophoblast using complementary DNA array screening. Biology of Reproduction 72 960-967. (https://doi. org/10.1095/biolreprod.104.034801)

Chen XQ, Wang SJ, Du JZ \& Chen XC 2007 Diversities in hepatic HIF1, IGF-I/IGFBP-1, LDH/ICD, and their mRNA expressions induced by $\mathrm{CoCl}(2)$ in Qinghai-Tibetan Plateau mammals and sea level mice. American Journal of Physiology: Regulatory, Integrative and Comparative Physiology 292 R516-R526. (https://doi.org/10.1152/ ajpregu.00397.2006)

Chen X, Liu J, He B, Li Y, Liu S, Wu B, Wang S, Zhang S, Xu X \& Wang J 2015 Vascular endothelial growth factor (VEGF) regulation by hypoxia inducible factor-1 alpha (HIF1A) starts and peaks during endometrial breakdown, not repair, in a mouse menstrual-like model. Human Reproduction 30 2160-2170. (https://doi.org/10.1093/humrep/dev156)

Coudyzer P, Lemoine P, Jordan BF, Gallez B, Galant C, Nisolle M, Courtoy PJ, Henriet P \& Marbaix E 2013 Hypoxia is not required for human endometrial breakdown or repair in a xenograft model of menstruation. FASEB Journal 27 3711-3719. (https://doi.org/10.1096/ fj.13-232074)

Cousins FL, Murray AA, Scanlon JP \& Saunders PT 2016 Hypoxyprobe reveals dynamic spatial and temporal changes in hypoxia in a mouse model of endometrial breakdown and repair. BMC Research Notes 930. (https://doi.org/10.1186/s13104-016-1842-8)

Critchley HO, Osei J, Henderson TA, Boswell L, Sales KJ, Jabbour HN \& Hirani N 2006 Hypoxia-inducible factor-1alpha expression in human endometrium and its regulation by prostaglandin E-series prostanoid receptor 2 (EP2). Endocrinology 147 744-753. (https://doi.org/10.1210/ en.2005-1153)

Escuin D, Kline ER \& Giannakakou P 2005 Both microtubule-stabilizing and microtubule-destabilizing drugs inhibit hypoxia-inducible factor1alpha accumulation and activity by disrupting microtubule function. Cancer Research 65 9021-9028. (https://doi.org/10.1158/0008-5472. CAN-04-4095)

Fan X, Krieg S, Kuo CJ, Wiegand SJ, Rabinovitch M, Druzin ML, Brenner RM, Giudice LC \& Nayak NR 2008 VEGF blockade inhibits angiogenesis and reepithelialization of endometrium. FASEB Journal 22 3571-3580. (https://doi.org/10.1096/fj.08-111401)

Finn CA \& Pope M 1984 Vascular and cellular changes in the decidualized endometrium of the ovariectomized mouse following cessation of hormone treatment: a possible model for menstruation. Journal of Endocrinology 100 295-300. (https://doi.org/10.1677/joe.0.1000295)

Fraser IS, Brown BW, Mattner PE \& Hutton BF 1982 Measurements of endometrial blood flow in anaesthetized ewes by xenon-133 clearance and microsphere techniques. Quarterly Journal of Experimental Physiology 67 531-535. (https://doi.org/10.1113/expphysiol.1982. sp002673)
Gaide Chevronnay HP, Lemoine P, Courtoy PJ, Marbaix E \& Henriet P 2010 Ovarian steroids, mitogen-activated protein kinases, and/or aspartic proteinases cooperate to control endometrial remodeling by regulating gene expression in the stroma and glands. Endocrinology 151 4515-4526. (https://doi.org/10.1210/en.2009-1398)

Gaide Chevronnay HP, Selvais C, Emonard H, Galant C, Marbaix E \& Henriet P 2012 Regulation of matrix metalloproteinases activity studied in human endometrium as a paradigm of cyclic tissue breakdown and regeneration. Biochimica and Biophysica Acta 1824 146-156. (https:// doi.org/10.1016/j.bbapap.2011.09.003)

Gannon BJ, Carati CJ \& Verco CJ 1997 Endometrial perfusion across the normal human menstrual cycle assessed by laser Doppler fluxmetry. Human Reproduction 12 132-139. (https://doi.org/10.1093/ humrep/12.1.132)

Hu Y, Liu J \& Huang H 2013 Recent agents targeting HIF-1 alpha for cancer therapy. Journal of Cellular Biochemistry 114 498-509. (https://doi. org/10.1002/jcb.24390)

Laird SM, Tuckerman EM, Dalton CF, Dunphy BC, Li TC \& Zhang X 1997 The production of leukaemia inhibitory factor by human endometrium: presence in uterine flushings and production by cells in culture. Human Reproduction 12 569-574. (https://doi.org/10.1093/humrep/12.3.569)

LaVallee TM, Zhan XH, Herbstritt CJ, Kough EC, Green SJ \& Pribluda VS 2002 2-Methoxyestradiol inhibits proliferation and induces apoptosis independently of estrogen receptors alpha and beta. Cancer Research $623691-3697$.

Li YF, Xu XB, Chen XH, Wei G, He B \& Wang JD 2012 The nuclear factorkappaB pathway is involved in matrix metalloproteinase-9 expression in RU486-induced endometrium breakdown in mice. Human Reproduction 27 2096-2106. (https://doi.org/10.1093/humrep/des110)

Markee JE 1940 Menstruation in intraocular transplants in the rhesus monkey. Contributions to Embryology of the Carnegie Institution 177 219-308.

Markee JE 1978 Menstruation in intraocular endometrial transplants in the rhesus monkey. American Journal of Obstetrics and Gynecology 131 558-559. (https://doi.org/10.1016/0002-9378(78)90119-9)

Maybin JA \& Critchley HO 2015 Menstrual physiology: implications for endometrial pathology and beyond. Human Reproduction Update $\mathbf{2 1}$ 748-761. (https://doi.org/10.1093/humupd/dmv038)

Maybin JA, Battersby S, Hirani N, Nikitenko LL, Critchley HO \& Jabbour HN 2011a The expression and regulation of adrenomedullin in the human endometrium: a candidate for endometrial repair. Endocrinology 152 2845-2856. (https://doi.org/10.1210/en.2010-1256)

Maybin JA, Hirani N, Brown P, Jabbour HN \& Critchley HO 2011b The regulation of vascular endothelial growth factor by hypoxia and prostaglandin F2\{alpha\} during human endometrial repair. Journal of Clinical Endocrinology and Metabolism 96 2475-2483. (https://doi. org/10.1210/jc.2010-2971)

Maybin JA, Hirani N, Jabbour HN \& Critchley HO 2011c Novel roles for hypoxia and prostaglandin E2 in the regulation of IL-8 during endometrial repair. American Journal of Pathology 178 1245-1256. (https://doi.org/10.1016/j.ajpath.2010.11.070)

Maybin JA, Murray AA, Saunders PTK, Hirani N, Carmeliet P \& Critchley HOD 2018 Hypoxia and hypoxia inducible factor-1alpha are required for normal endometrial repair during menstruation. Nature Communications 9 295. (https://doi.org/10.1038/s41467-017-02375-6)

Milligan SR \& Cohen PE 1994 Silastic implants for delivering physiological concentrations of progesterone to mice. Reproduction, Fertility, and Development 6 235-239. (https://doi.org/10.1071/rd9940235)

Raleigh JA, Calkins-Adams DP, Rinker LH, Ballenger CA, Weissler MC, Fowler WC, Novotny DB \& Varia MA 1998 Hypoxia and vascular endothelial growth factor expression in human squamous cell carcinomas using pimonidazole as a hypoxia marker. Cancer Research 58 3765-3768.

Roh CR, Budhraja V, Kim HS, Nelson DM \& Sadovsky Y 2005 Microarraybased identification of differentially expressed genes in hypoxic term human trophoblasts and in placental villi of pregnancies with growth restricted fetuses. Placenta 26 319-328. (https://doi.org/10.1016/j. placenta.2004.06.013)

Rudolph-Owen LA, Slayden OD, Matrisian LM \& Brenner RM 1998 Matrix metalloproteinase expression in Macaca mulatta endometrium: evidence for zone-specific regulatory tissue gradients. Biology of Reproduction $\mathbf{5 9}$ 1349-1359. (https://doi.org/10.1095/biolreprod59.6.1349) 
Slayden OD \& Brenner RM 2006 A critical period of progesterone withdrawal precedes menstruation in macaques. Reproductive Biology and Endocrinology 4 (Supplement 1) S6. (https://doi.org/10.1186/14777827-4-S1-S6)

Soares MJ, Chakraborty D, Renaud SJ, Kubota K, Bu P, Konno T \& Rumi MA 2012 Regulatory pathways controlling the endovascular invasive trophoblast cell lineage. Journal of Reproduction and Development 58 283-287. (https://doi.org/10.1262/jrd.2011-039)

Sugino N, Karube-Harada A, Taketani T, Sakata A \& Nakamura Y 2004 Withdrawal of ovarian steroids stimulates prostaglandin F2alpha production through nuclear factor-kappaB activation via oxygen radicals in human endometrial stromal cells: potential relevance to menstruation. Journal of Reproduction and Development 50 215-225. (https://doi. org/10.1262/jrd.50.215)

Tsuzuki T, Okada H, Cho H, Tsuji S, Nishigaki A, Yasuda K \& Kanzaki H 2012 Hypoxic stress simultaneously stimulates vascular endothelial growth factor via hypoxia-inducible factor-1alpha and inhibits stromal cell-derived factor-1 in human endometrial stromal cells. Human Reproduction 27 523-530. (https://doi.org/10.1093/humrep/der405)

Wang Q, Xu X, He B, Li Y, Chen X \& Wang J 2013 A critical period of progesterone withdrawal precedes endometrial breakdown and shedding in mouse menstrual-like model. Human Reproduction 28 1670-1678. (https://doi.org/10.1093/humrep/det052)

Wang SF, Chen XH, He B, Yin DD, Gao HJ, Zhao HQ, Nan N, Guo SG, Liu JB, Wu B et al. 2019 Acute restraint stress triggers progesterone withdrawal and endometrial breakdown and shedding through corticosterone stimulation in mouse menstrual-like model. Reproduction 157 149-161. (https://doi.org/10.1530/REP-18-0163)

Wu B, Chen X, He B, Liu S, Li Y, Wang Q, Gao H, Wang S, Liu J, Zhang S et al. 2014 ROS are critical for endometrial breakdown via NF-kappaBCOX-2 signaling in a female mouse menstrual-like model. Endocrinology 155 3638-3648. (https://doi.org/10.1210/en.2014-1029)

Xi L, Taher M, Yin C, Salloum F \& Kukreja RC 2004 Cobalt chloride induces delayed cardiac preconditioning in mice through selective activation of HIF-1alpha and AP-1 and iNOS signaling. American Journal of
Physiology: Heart and Circulatory Physiology 287 H2369-H2375. (https://doi.org/10.1152/ajpheart.00422.2004)

Xu X \& He B 2012 VEGFNEGFR-2 mRNA expression in a mouse menstrual-like model by pharmacologic progesterone withdrawal. Journal of Animal and Veterinary Advances 11 3512-3516. (https://doi. org/10.3923/javaa.2012.3512.3516)

Xu XB, He B \& Wang JD 2007 Menstrual-like changes in mice are provoked through the pharmacologic withdrawal of progesterone using mifepristone following induction of decidualization. Human Reproduction 22 3184-3191. (https://doi.org/10.1093/humrep/dem312)

Xu X, Chen X, Li Y, Cao H, Shi C, Guan S, Zhang S, He B \& Wang J 2013 Cyclooxygenase-2 regulated by the nuclear factor-kappaB pathway plays an important role in endometrial breakdown in a female mouse menstrual-like model. Endocrinology 154 2900-2911. (https://doi. org/10.1210/en.2012-1993)

Yuan Y, Hilliard G, Ferguson T \& Millhorn DE 2003 Cobalt inhibits the interaction between hypoxia-inducible factor-alpha and von HippelLindau protein by direct binding to hypoxia-inducible factor-alpha. Journal of Biological Chemistry 278 15911-15916. (https://doi. org/10.1074/jbc.M300463200)

Zhang J \& Salamonsen LA 2002 Expression of hypoxia-inducible factors in human endometrium and suppression of matrix metalloproteinases under hypoxic conditions do not support a major role for hypoxia in regulating tissue breakdown at menstruation. Human Reproduction 17 265-274. (https://doi.org/10.1093/humrep/17.2.265)

Received 31 October 2018

First decision 6 December 2018

Revised manuscript received 14 November 2019

Accepted 19 November 2019 